\title{
Selective Detection of Sulfur-Containing Compounds by Gas Chromatography/Chemical Reaction Interface Mass Spectrometry
}

\author{
Mehdi Moini*, Donald Chace ${ }^{\dagger}$, and Fred P. Abramson \\ Department of Pharmacology. The George Washington University Medical Center, Washington, D.C., USA
}

Addition of a reactant gas to a low pressure microwave-induced plasma creates a reaction interface in which complex molecules are converted into small polyatomic neutral species. For a given reactant gas the array of these small molecules reflects the elemental composition of the original analyte. In this study $\mathrm{HCl}$ has been found highly effective as a reactant gas for selective detection of sulfur-containing compounds using capillary gas chromatography/chemical reaction interface mass spectrometry. Detection limits as low as $30 \mathrm{pg}$ of a sulfur-containing compound and a dynamic range of two orders of magnitude were achieved. (J Am Soc Mass Spectrom 1991, 2, 250-255)

$\mathrm{T}$ The capability of combining compound-independent, sensitive, and selective elemental and isotopic detection with an efficient separation process like gas or liquid chromatography is highly desired in many areas of natural science including chemistry, biochemistry, pharmacology, and petroleum analysis.

The microwave-powered chemical reaction interface (CRI) has been used to convert complex organic molecules in the presence of a reactant gas into small stable molecules that are detected by mass spectrometry (CRIMS) [1, 2]. For a given reactant gas the array of molecules formed reflects the elemental composition of the original analyte. Recently, applications of this system for selective detection of ${ }^{13} \mathrm{C},{ }^{15} \mathrm{~N},{ }^{2} \mathrm{H}$, and ${ }^{14} \mathrm{C}[3-6]$ were published. Isotopic nitrogen detection by emission and mass spectrometry was previously reviewed [7].

Selective detection of sulfur-containing compounds has received considerable attention primarily due to the importance of the compounds in environmental, industrial, and medical fields. A radio frequency plasma detector has been used for sulfur-selective capillary gas chromatographic (GC) analysis of fossil fuels [8]. Reduction of sulfur-containing compounds to $S F_{6}$ by fluorination with $F_{2}$ on a heated $\mathrm{Ag}$ catalyst after GC separation and its detection using electron capture was reported [9]. Inductively coupled atomic

\footnotetext{
*Present address: Department of Chemistry, The University of Texas at Austin, Austin, TX 78712

${ }^{\dagger}$ Present address: Division of Pediatric Genetics and Metabolism, Duke University Medical Center, Durham, NC 27710.

Address reprint requests to Fred P. Abramson, Department of Pharmacology, The George Washington University Medical Center, Washington, DC 20037
}

emission spectrometry of sulfur in the vacuum ultraviolet has also been employed to determine the concentration of several micromolar solutions of proteins with known sulfur contents [10]. The flame photometric detector was used for the analysis of organosulfur compounds by supercritical fluid chromatography [11]. In general, these techniques demonstrate selectivily and sensitivity, but they all lack the flexibility of a GC/MS system. We previously reported on the direct introduction analysis of sulfur content of proteins by CRIMS [12].

In this article we describe an improved chemical strategy to enable selective and sensitive mass spectrometric detection of sulfur-containing compounds and demonstrate its performance. This system combines an efficient separation process, in this case capillary GC, with a mass spectrometer while maintaining the chromatographic resolution and conventional GC/MS capability.

\section{Experimental}

The capillary gas chromatograph/chemical reaction interface mass spectrometer was described previously [4]. A 2450- $\mathrm{MHz}$ microwave cavity was placed inside a GC column oven and was operated at approximately $70 \mathrm{~W}$ of forward power and $5 \mathrm{~W}$ or less of reflected power. A Hewlett-Packard (Palo Alto, CA) Model 5830A GC with a split/splitless capillary adapter was used with a $30-\mathrm{m}$ DB-5, 0.25-mm i.d., $0.25-\mu \mathrm{m}$ film thickness capillary column (J \& W Scientific, Rancho Cordova, CA). This column was connected to a 1/16" Swagelok tee into which also flowed the reactant gas. The output of this tee was coupled via a $1 / 16^{\prime \prime}$ to $1 / 4^{\prime \prime}$ adapter to a $4^{\prime \prime}$ long, $1 / 4^{\prime \prime}$ o.d., 
1/32" i.d. ceramic tube (Scientific Instrument Services, Ringoes, NJ) using conventional stainless steel Swagelok hardware and tubing, and 5\% Vespel/graphite ferrules (Alltech Associates, State College, PA). The output end of this tube was connected to the mass spectrometer using deactivated, uncoated widebore (0.53 mm i.d.) fused silica tubing (J \& M) housed in a heated $\left(250{ }^{\circ} \mathrm{C}\right)$ stainless steel tube. The flow of reactant gas was adjusted using a Granville-Phillips (Boulder, CO) Series 203 variable leak.

A tank of ultrapure carrier grade helium (Air Products, Allentown, PA) was fitted with a high purity stainless steel diaphragm regulator (Matheson, East Rutherford, NJ) and operated at a pressure of $40 \mathrm{psi}$, producing a helium flow of 1-2 $\mathrm{mL}$ min. Helium served both as the carrier gas for the GC and the bulk gas in the microwave-induced plasma. Ultrapure carrier grade oxygen and a standard grade of anhydrous hydrogen chloride (Air Products) were used as reactant gases. Oxygen in the amount used in this study was not harmful to the tungsten filament of this mass spectrometer as it was in the previous study [4] with another mass spectrometer that used a thoriated iridium filament. A Tesla coil (vacuum leak detector, Fisher Scientific, Pittsburgh, PA) was occasionally required to initiate the plasma. To avoid quenching the plasma, or the buildup of soot, the plasma was always turned off when the solvent was eluting. The reactant gas tanks were connected to the variable leak using stainless steel regulators (Matheson) and $1 / 16^{\prime \prime}$ o.d., $0.01^{\prime \prime}$ i.d. stainless steel tubing. The carrier and reactant gas lines and regulators were pre-evacuated prior to use to remove air and contaminants.

An Extrel C50/400 mass spectrometer (Pittsburgh, PA) with $4^{\prime \prime}$ diffusion pumps at the source and the analyzer was used. The mass spectrometer was controlled by a Teknivent (Maryland Hts., MO) data acquisition interface, software, and an IBM PC-AT computer. For the CRIMS studies of phenytoin metabolism, the initial GC temperature was $130^{\circ} \mathrm{C}$. After a 1 min delay, the column was temperature programmed at $5{ }^{\circ} \mathrm{C} / \mathrm{min}$ to $250{ }^{\circ} \mathrm{C}$ and held an additional $5 \mathrm{~min}$. Chromatograms showing only enriched isotopes were produced in the CALC channel of the Teknivent software using the following formula $[3,4]$ :

$$
\begin{aligned}
& \text { Intensity of enriched isotope } \\
& =\text { peak intensity observed at } M+1 \\
& \quad \text { - natural abundance of } M+1 \text { expected } \\
& \quad \text { from peak intensity at } M
\end{aligned}
$$

To enhance sensitivity when trying to identify sulfur-containing peaks, two limited mass ranges were used in the scanning experiments: 75-250 $\mathrm{u}$ and $250-450 \mathrm{u}$. This allowed longer integration times that improved the spectral quality. Also, the temperature program was slowed from $5{ }^{\circ} \mathrm{C} / \mathrm{min}$ to $2.5^{\circ} \mathrm{C} / \mathrm{min}$ to improve chromatographic resolution.
Thiopental (Fisher) and $2-{ }^{13} \mathrm{C}-, 1,3-{ }^{15} \mathrm{~N}_{2}$-phenobarbital (99 atom \%, Cambridge Isotope Laboratories, Woburn, MA) were used without further purification. The samples for urine analysis came from our previous work [4] and were prepared according to that reference, except that thiopental $(50 \mathrm{ng} / \mu \mathrm{L}$ in the final solution) was also added as an internal standard for sulfur. This process involves extractive ethylation of all acidic hydrogens with ethyl iodide and tetrabutylammonium hydroxide, and trifluoroacetylation of all other active hydrogens with trifluoroacetylimidazole. Solutions of $0.1 \mu \mathrm{g} / \mathrm{mL}$ to $10 \mu \mathrm{g} / \mathrm{mL}$ of thiopental with constant amounts $(20 \mu \mathrm{g} / \mathrm{mL})$ of phenobarbital in ethanol were used for the linearity study. Dilute solutions of simple sulfur-containing compounds, such as dimethylsulfoxide, were used in the initial studies of $\mathrm{HCl}$ CRIMS chemistry. Thiopental is the only substance that was thoroughly tested.

\section{Results and Discussion}

\section{Chemistry}

In a low pressure microwave-induced helium plasma, with the thermodynamic temperature of about $4000-6000{ }^{\circ} \mathrm{K}[13,14]$, the components eluting from a GC column are completely decomposed. When the products of this decomposition leave the hot region of this plasma they react rapidly with the reactant gas that was added to the helium gas flow to produce thermodynamically stable neutral molecules. The mass spectra of selected neutral molecules identify and quantify the elements of interest. For example, when oxygen is used as a reactant gas, carbon forms $\mathrm{CO}$ and $\mathrm{CO}_{2}$, nitrogen predominantly forms $\mathrm{N}_{2}$ with ca. $10 \% \mathrm{NO}$, and hydrogen forms $\mathrm{H}_{2} \mathrm{O}$. Detection of ions with $m / z 30,31,44$, and 45 in the selected ion monitoring mode represent: ${ }^{14} \mathrm{NO} ;\left({ }^{15} \mathrm{NO}+\mathrm{N}^{17} \mathrm{O}\right)$; ${ }^{12} \mathrm{CO}_{2}$; and $\left({ }^{12} \mathrm{C}^{17} \mathrm{O}^{16} \mathrm{O},+{ }^{13} \mathrm{CO}_{2}\right)$, respectively. A chromatogram showing only isotopically enriched compounds can be oblained by subtracting the nalural abundance contribution of $\mathrm{CO}_{2}$ and $\mathrm{NO}$ as determined from the observed signals at $m / z$ 44 and 30 from the signals observed at $\mathrm{m} / z 45$ and 31 , respectively [3-5].

Attempts to detect selectively sulfur-containing compounds as $\mathrm{SO}$ at $m / z 48$, or $\mathrm{SO}_{2}$, at $m / z 64$, or $\mathrm{SO}_{3}$ at $m / z 80$ with oxygen as a reactant gas were not totally successful; performance was irreproducible. We believe this was due to a reaction sequence such as:

$$
\begin{gathered}
\text { Organic sulfur compounds }+\mathrm{O}_{2} \\
\rightarrow \mathrm{SO}_{2}+\mathrm{H}_{2} \mathrm{O}+\mathrm{CO}_{2}+\cdots \\
\mathrm{SO}_{2}+\mathrm{H}_{2} \mathrm{O} \rightarrow \mathrm{H}_{2} \mathrm{SO}_{3} \text { (nonvolatile) }
\end{gathered}
$$

Therefore, as long as free water was present in the plasma, sulfur probably produced absorptive complexes. In order to solve this problem a gas with completely different chemistry was used. One idea 
was to have a very polar reactant gas so that it would scavenge the water that was formed, thus assuring transmission of the sulfur species. Another idea was to use a different chemistry so that a more transmissible species would be formed. $\mathrm{HCl}$ was the first gas of this nature that was tried, and it worked very well.

Due to imperfections in the vacuum envelope and impurities in the gases used there was always oxygen and nitrogen present in the plasma. When $\mathrm{HCl}$ gas was added to this plasma there were two possibilities:

1. If the amount of $\mathrm{HCl}$ gas was not enough to titrate completely the oxygen present in the plasma then:

$$
\mathrm{HCl}+\mathrm{O}_{2} \rightarrow \mathrm{H}_{2} \mathrm{O}+\mathrm{ClO}_{2}+\mathrm{O}_{2}
$$

In this case sulfur still reacted according to reactions 1 and 2 .

2. When $\mathrm{HCl}$ was present in excess then:

$$
\begin{gathered}
(x s) \mathrm{HCl}+\mathrm{O}_{2} \rightarrow \mathrm{H}_{2} \mathrm{O}+\mathrm{Cl}_{2}+\mathrm{H}_{2}+\mathrm{HCl} \\
\mathrm{HCl}+\mathrm{H}_{2} \mathrm{O} \rightarrow \text { complex }
\end{gathered}
$$

Organic sulfur compounds $+\mathrm{HCl} \rightarrow \mathrm{SCl}+\mathrm{HCN}$ $+\cdots$

The disappearance of $\mathrm{ClO}_{2}$ at $\mathrm{m} / z$ 67 and 69 and the formation of $\mathrm{Cl}_{2}$ at $m / z 70,72$, and 74 were indicative of correct conditions for the sulfur studies. In this case sulfur predominantly ( $>95 \%$ ) produced $\mathrm{SCl}$ at $\mathrm{m} / \mathrm{z}$ 67 and 69. Other minor ions represented $\mathrm{SCl}_{2}$. One should note that due to dissociation in the ion source, the ions detected in the mass spectrometer do not necessarily represent the ratio of neutrals formed in the chemical reaction interface. Because the relative abundance of the molecular ion of $\mathrm{SCl}_{2}$ is $60 \%$ of the base peak at $m / z 67$, we know that the $\mathrm{SCl}$ observed is not solely due to fragmentation of ground-state $\mathrm{SCl}_{2}$. Similarly, the signal at $\mathrm{m} / z 67$ cannot be a fragment of $\mathrm{S}_{2} \mathrm{Cl}_{2}$ because it also has prominent ions at higher mass that would have been observed in our experiments. We therefore have no determination of whether $\mathrm{SCl}^{+}$arises as a highly abundant fragment from a larger molecule that remains in an excited state following its exit from the plasma or whether $\mathrm{SCl}$ exists as a separate chemical entity. When the oxygen titration procedure described above was carried out, relatively more $\mathrm{HCl}$ was needed as a reactant gas than when oxygen was used.

The HCl-scavenged plasma generates a reducing environment, much as if it were a hydrogenscavenged plasma [4]. Carbonaceous materials produce hydrocarbons, for example, $\mathrm{CH}_{4}$ and $\mathrm{C}_{2} \mathrm{H}_{2}$, and chlorocarbons of the type $\mathrm{C}_{\mathrm{n}} \mathrm{H}_{\mathrm{m}} \mathrm{Cl}_{\mathrm{p}}$, although in the presence of excess nitrogen these can react further to form $\mathrm{HCN}$ at $m / z 27$. Organic nitrogen in the presence of carbon also predominantly produced $\mathrm{HCN}$. Therefore, the chromatogram obtained at $m / z 27$ represented a nonselective carbon/nitrogen channel while $m / z 67$ represented a selective sulfur channel. As

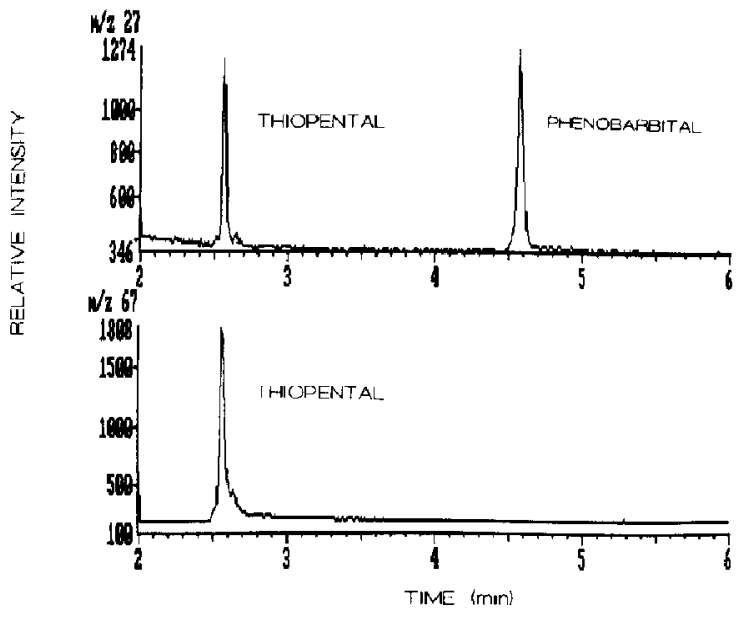

Figure 1. Selective detection of sulfur at $m / z \quad 67$ using a mixture of thiopental (6.6 $\mathrm{ng}$ on-column) and phenobarbital (26.4 $\mathrm{ng}$ on-column). The chromatogram at $m / z 27$ (HCN) is a nonselective carbon channel.

long as the plasma is not on when the solvent elutes, no soot or particulate build-up occurs with this chemical reaction system. This parallels our experiences with $\mathrm{SO}_{2}$ and $\mathrm{H}_{2}$ as reactant gases [4].

\section{Selectivity}

Detection at $m / z 67$ was completely selective for sulfur. The selectivity of this detection channel was demonstrated using thiopental and phenobarbital as examples of sulfur- and nonsulfur-containing compounds. The GC/CRIMS chromatograms are shown in Figure 1 in which $m / z 27$ represents a nonselective channel while $m / z$ 67 represents the selective sulfur channel. The small peak on the shoulder of the thiopental peak is seen in both channels and is assumed to be an impurity.

\section{Sensitivity and Dynamic Range}

Sensitivity and dynamic range for sulfur in GC/CRIMS were studied using thiopental as a sulfur-containing compound and phenobarbital as an internal standard. Detection at $m / z 67$ was completely selective, so a limit of $30 \mathrm{pg}$ for thiopental on-column at a signal-to-noise ratio of 10 was achieved in the single ion detection mode with $300 \mathrm{~ms}$ integration time. The linear dynamic range of the calibration curve is shown in Figure 2. One microliter of each solution was injected in the splitless mode. Two ions ( $\mathrm{HCN}, m / z 27$ and SCl, $m / z 67$ ) were acquired with $150 \mathrm{~ms}$ integration times. The $\mathrm{m} / \mathrm{z} 67$ thiopental signal was normalized with respect to the $m / z 27$ phenobarbital signal. The lower limit of $100 \mathrm{pg}$ represents the lowest amount that can be successfully determined using the shorter integration times required by multiple ion sampling. The $10,000 \mathrm{pg}$ upper value 


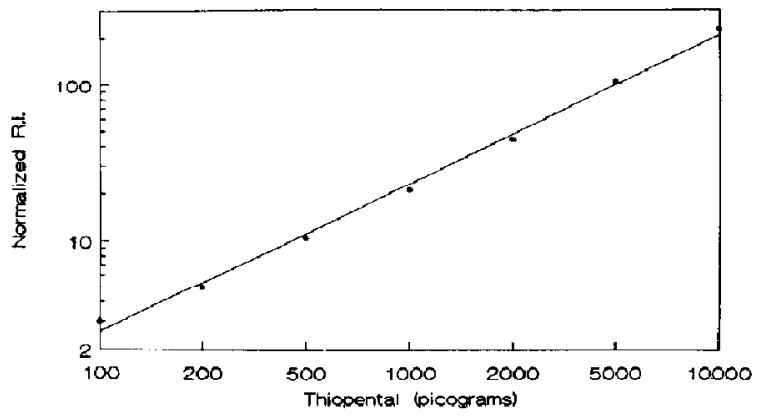

Figure 2. Linearity of sulfur detection at $m / z 67$ using thiopental. The integrated area has been normalized to the integrated area in the $m / z 27$ channel for phenobarbital, the internal standard.

simply represents the largest amount of material we chose to analyze. We did not actually determine the upper limit of linearity, but do know that ca. tenfold higher amounts overwhelm the capacity of the plasma chemistry.

\section{Application to Metabolism Studies}

Selective detection of ${ }^{13} \mathrm{C}$ - and ${ }^{15} \mathrm{~N}$-labeled phenytoin and its metabolites in urine following separation by gas chromatography was recently studied by GC/CRIMS $[3,4]$. There $\mathrm{SO}_{2}$ was used as a reactant gas. Because the present goal was sulfur detection, we did not want to use the sulfur-containing reactant gas $\mathrm{SO}_{2}$ where the possibility of sulfur residues exists. Such interference had not been seen in preliminary experiments, however, we thought it was judicious to avoid $\mathrm{SO}_{2}$. Therefore, we employed oxygen as the reactant gas. To demonstrate the selectivity of the sulfur channel in a complex chemical environment and to study the possibility of sulfur-containing phenytoin metabolites, the same urine sample from a phenytoin-treated dog that was previously obtained [4] was used again. We repeated this analysis to compare the present GC/MS system with the previous one.

Chromatograms showing nonselective ${ }^{12} \mathrm{C}$ and enriched ${ }^{13} \mathrm{C}$ and ${ }^{15} \mathrm{~N}$ are shown in Figure 3. These chromatograms are almost identical to those previously published both in terms of relative elution time and intensity $[3,4]$. The absolute elution times are different because this work used a different GC with different temperature programming capability.

Examination of urine for sulfur-containing compounds was then performed using $\mathrm{HCl}$ as a reactant gas. The result is shown in Figure 4, in which the nonselective channel (HCN, $m / z 27$ ) is shown at the top and the selective sulfur channel ( $\mathrm{SCl}, m / z 67$ ) is shown at the bottom. These chromatograms were generated using a temperature program half the rate as the stable isotope study seen in Figure 3. The $\mathrm{SCl}$ signal for the internal standard, thiopental r.t. $=13+$ min, is representative of approximately $50 \mathrm{ng}$ on-col-

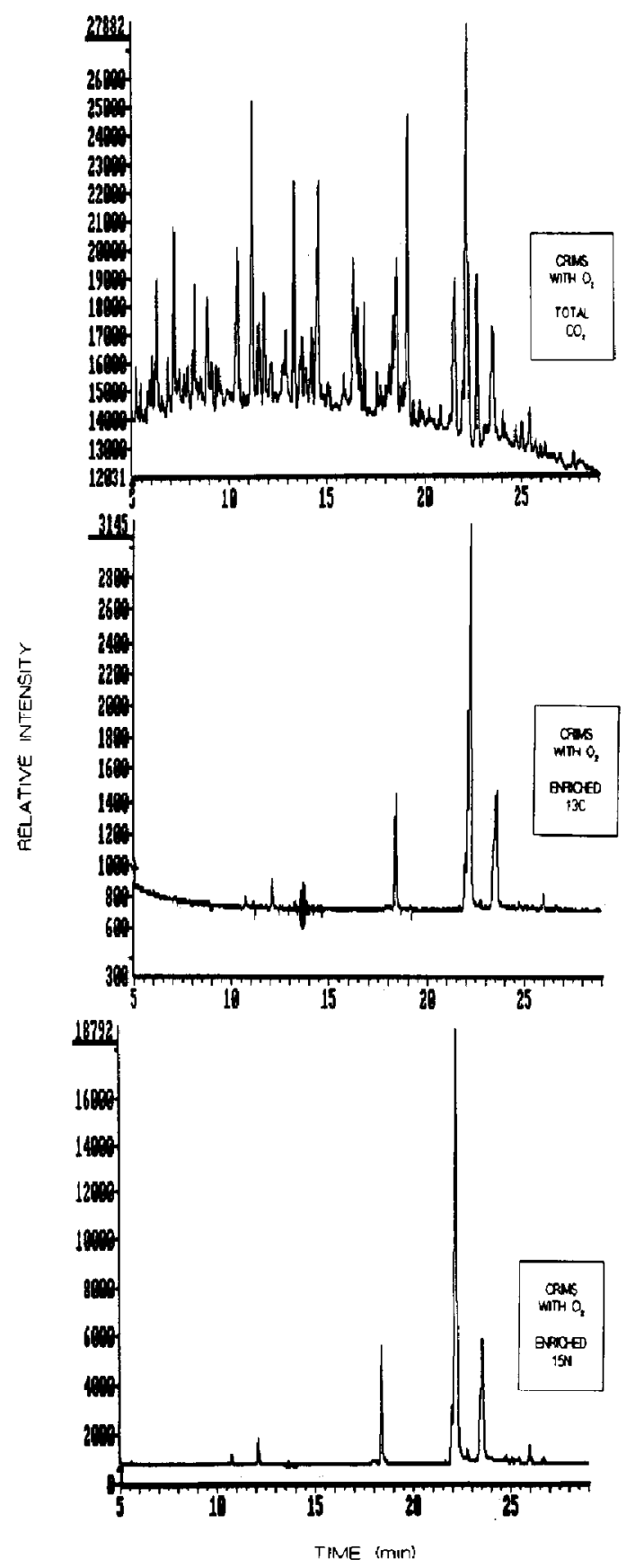

Figure 3. GC/CRIMS using oxygen reactant gas for selective isotopic analysis of urine from a dog treated with $2-{ }^{13} \mathrm{C}-, 1,3-$ ${ }^{15} \mathrm{~N}_{2}$-phenytoin. The upper trace shows nonselective carbon detection; the middle trace shows selective detection of enriched ${ }^{13} \mathrm{C}$; and the lower trace shows selective detection of enriched ${ }^{15} \mathrm{~N}$. 


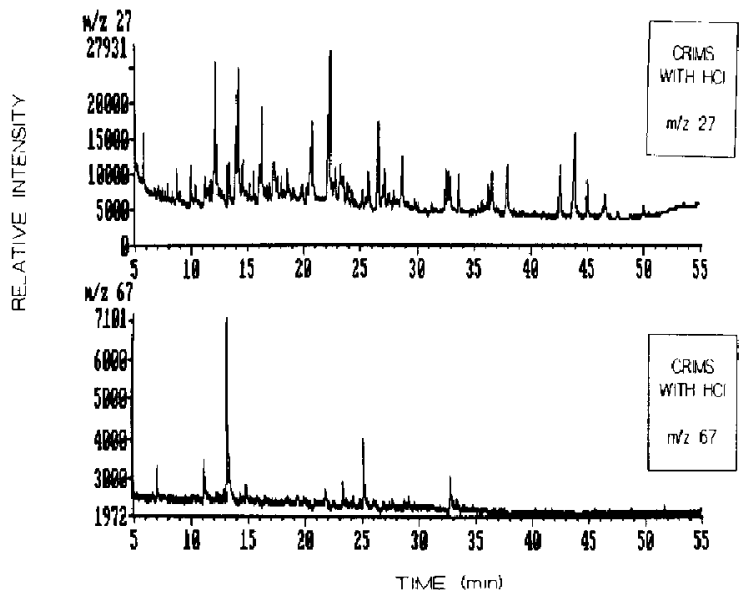

Figure 4. GC/CRIMS using $\mathrm{HCl}$ reactant gas for sulfur-selective detection. The upper trace shows nonselective carbon/ nitrogen detection; the lower trace shows selective sulfur detection.

umn. Two of these sulfur peaks, at retention times of 46.0 and $49.1 \mathrm{~min}$, are phenytoin metabolites. With the normalization done in Figure 4, these peaks are not prominent, but by expanding subzones of time and intensity (Figure 5), distinct peaks at these retention times were noted. Their spectra, which are shown in Figure 6, are consistent with positional isomers of aromatic monothiol phenytoin as previously suggested [15], but without the chemical specificity of the current method. In our previous chromatograms [4] these two peaks appear at 26.3 and $28.5 \mathrm{~min}$. Further

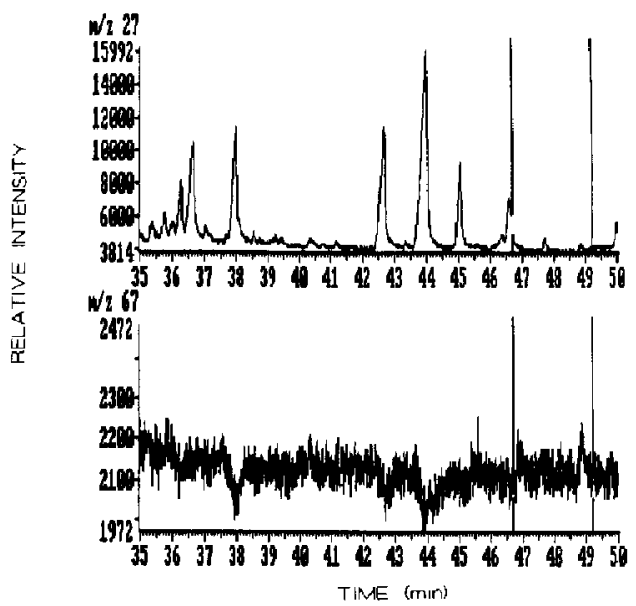

Figure 5. Expanded $x$ and $y$ axes view of the chromatograms from Figure 4. The cursors are placed at the edges rather than at the centers of the two peaks to show their alignment in the selective channel onto the nonselective chromatogram without obscuring the peaks.
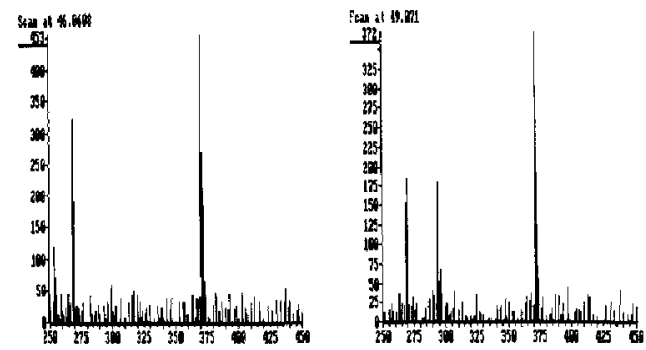

Figure 6. Mass spectra of sulfur-containing phenytoin metabolites. The highest mass observed, $m / z 371$, is appropriate for the molecular ion of the triethyl derivative of monothiophenytoin with three heavy isotopes. In parallel with the hydroxylated metabolites of phenytoin, the two peaks presumably represent positional isomers, for example, metathiophenytoin and parathiophenytoin.

studies need to be undertaken to identify the unknown sulfur-containing peaks at r.t. $=7,11,25$, and $33 \mathrm{~min}$ in Figure 4. It should be noted that the animals were not fasted throughout the period of urine collection, so some of these might be of dietary origin. They were not derived from phenytoin.

Chemical reaction interface mass spectrometry is a technique that can be used both as a selective element and stable isotope detector. Its low detection limits, minimum instrumental modification and simplicity make it an attractive tool in metabolism, environmental, and industrial investigations. We have shown here that one can switch from a study of isotopes such as ${ }^{13} \mathrm{C}$ and ${ }^{15} \mathrm{~N}$ to selective detection of sulfur by simply changing from one reactant gas (e.g., $\mathrm{O}_{2}$ ) to another (e.g., $\mathrm{HCl}$ ).

\section{Acknowledgments}

This work was supported by USPHS grant no. NIH GM-36143. A preliminary report of this work was presented at the 37th ASMS Conference on Mass Spectrometry and Allied Topics, Miami Beach, FL, May 1989.

\section{References}

1. Markey, S. P.; Abramson, F. P. Amal. Chem. 1982, 54, 2375-2376.

2. Heppner, R. A. Anal. Chem. 1983, 55, 2170-2174.

3. Chace, D. H.; Abramson, F. P. In Synthesis and Applications of Isotopically Labelled Compounds, 1988; Baillie, T. A.; Jones, J. R., Eds.; Elsevier: Amsterdam, 1989; p. 253.

4. Chace, D. H.; Abramson, F. P. Anal. Chem. 1989, 61, 2724-2730.

5. Chace, D. H.; Abramson, F. P. Biomed. Environ. Mass Spectrom. 1990, 19, 117-122.

6. Chace, D. H.; Abramson, F. P. J. Chromatogr, 1990, 527, 1- 10.

7. Fiedler, R.; Proksch, G. Anal. Chim. Acta 1975, 78, 1-62.

8. Skelton, Jr., R. J.; Chang, H.-C. K.; Farnsworth, P. B.; Markides, K. E.; Lee, M. L. Anal. Chem. 1989, 61, 2292-2298. 
9. Johnson, J. E.; Lovelock, J. E. Anal, Chem. 1989, 60, 812-816. 10. Bongers, J.; Walton, C. D.; Richardson, D. E.; Bell, J. U. Anal Chem. 1988, 60, 26832686.

11. Olesik, S. V.; Pekay, L. A.; Paliwoda, E. A. Anal. Chem. 1989, 61, 58-65.

12. Abramson. F. P.; Markey, S. P. Biomed. Environ. Mass Spectrom. 1986, 13, 411-415.
13. Matousek, J. P.; Orr, B. J.; Selby, M. Prog. Analyt. Atom. Spectrosc. 1984, 7, 275-314.

14. Moini, M; Abramson, F. P., unpublished results.

15. Chase, D. H. Ph. D. dissertation; Department of Pharmacology, Graduate School of Arts and Sciences, George Washington University, 1989. 